\title{
Society, Art and Technology-Innovation Origin of Interaction Design
}

\author{
Hu Xiaochen
}

China Academy of Art, Hangzhou, Zhejiang, China, 310002

xiaochen9@163.com

Keywords: interaction design, information technology revolution, innovation, socialized thinking, altruism.

\begin{abstract}
Interaction design is a kind of human-centered design. It considers the relationship between people and information society or technology products as a part of the nature laws. Interaction design research is the research of the future life style and society demands. Therefore, it can push social development and meet the society demands through the science and technology progress. This paper analyzes the innovation origin of interaction design, and then discusses the integrating innovation of design, art, science, technology and society.
\end{abstract}

\section{Introduction}

"Design" is the third kind of human wisdom, which combines the elements of "art" and "science and technology". Interaction design is a special design field which rapidly formed accompanied by information technology revolution era. Compared with the traditional design, interaction design can be considered as a new design structure system. The driver promoting interactive design to bring social innovation, concept innovation and product innovation is the source of power to bridge the social, art and technology.

\section{Innovation Reform brought by Socialized Thinking}

\section{Socialized Thinking in Designs}

Dean.Peter Rowe, a Harvard Design Institute professor,defined the word "Design Thinking"in the book of Design Thinking in 1987. In 1991, David Kelley founded the IDEO, which is the world's largest design consultancy at present. And later, he also founded the D. School of Stanford, successfully implemented design thinking into design work and made it commercialization. The difference between the thinking designand the traditional design thinking is that the thinking design focuses on the social issues. The characteristic of interaction design is that it is not done for a particular person; usually it serves a group or the whole society. In the design of the project, the social effects of the design products need to be considered, and the balance between social value and commercial value is obtained.For example, in recent years the domestic institutions of higher art often put forward "research" teaching mode, advocate the commercial project is the introduction of the study, to obtain the transformation of research achievements of economic indicators as a measure of research performance rating criteria. While the author visited the United States and Europe several famous universities, the discovery of "research" combination of teaching mode or the project teaching mode, and the project design is more concerned about the social value of the design. In the process of the election of design projects of RISD, NYU, CCA, SVA, etc. the projects focusing on social issues or public welfare account for a major part. In all into the design thinking of the curriculum design school, attention to the social and public interest of the theme of the project occupies the majority. The first step of design thinking is empathize (Figure 1). Empathy is to help others at the same time by egoism and altruism to consider the impact of, especially when we feel with somebody has a connection, we will be able to generate empathy. In the design process, we do everything that might stand in the user's point of view, observing user behavior, understanding users what to do and why, what is the purpose, in order to better the design product is accepted by the user. For example, the project in Rhode Island School of Design has changedthe 
world by changing the health care service; the project of Poverty Simulation in Stanford University has helped students pay attention to social values of designs.

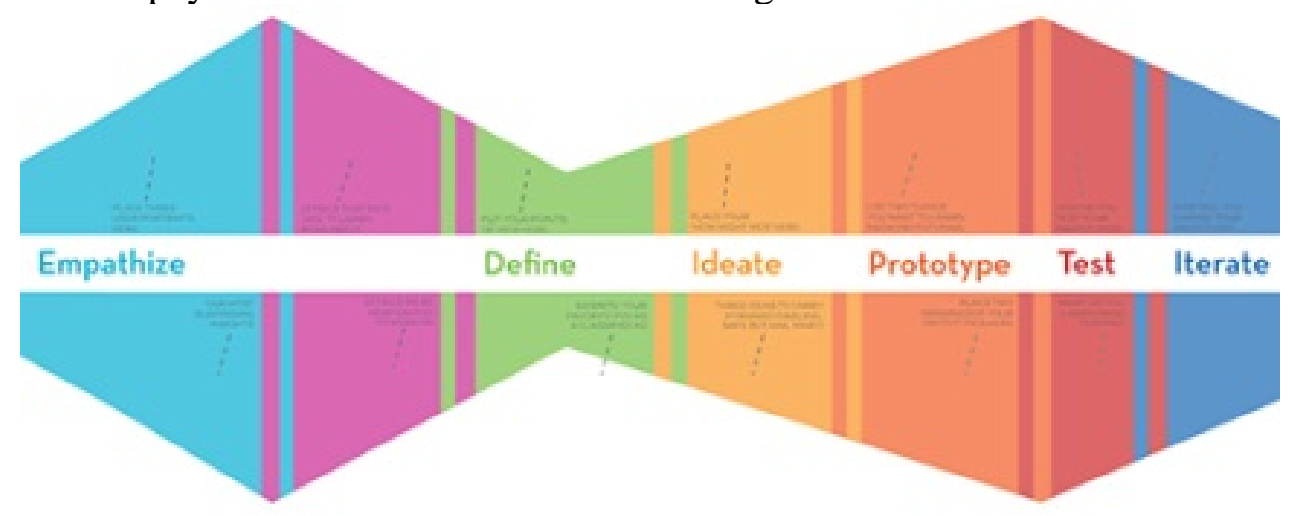

Figure 1 Process of Design Thinking

\section{Influence of Altruism}

It's not difficult to find that designers do not expect to obtain economic benefits from the product itselfin product design process and also support the user use the product through economic means from the case of the huge success of Uber and Airbnb on mobile Internet service platform. Also the design of the product itself is to promote the social idle resources reuse as a starting point, users through their idle vehicles and rental housing to solve the contradiction between the shortage of social resources and in order to get feedback. This has proved that the product and service from the user's point of view based on the norm reciprocity is more likely to be accepted. In such a social network and mutual help us understand the meaning of "social capital", support the connection, information communication, trust and cooperation, so as to make the Uber and Airbnb such mobile Internet platform for normal operation, and were commercial success.From the point of view of interactive design products with Altruism products appear to mark the product design thinking innovation. Based on the interactive product of the mobile Internet, because of its characteristic of altruism, the creative development of the Internet has been developed in the application of the product. So that the use of public services and social idle resources to use as the design objectives of the product more easily accepted by the community, is used by users. From the interaction designer's point of view, only to the commercial profits for the purpose of design in emotion is very difficult to move the user and the designer will due to the lack of commercially driven design and creative, only with social responsibility, with altruism designers to design products more humane care, social innovation spirit. The first step in the design thinking is Empathize (empathy), and empathy is to help others all at the same time egoism and altruism to consider the impact of, especially when we feel with somebody have a connection, we will be able to generate empathy. In the design process, we do everything that might stand in the user's point of view, observing user behavior, understanding what to do and why, what is the purpose in order to make thedesign product is accepted by the users.

\section{Diversification of Interaction brought by Science and Technology}

Human-computer interaction field is very wide, which ranges from the early electronic games, electronic pets, robot to the Xbox 360, Wii, PS3 sense of the gamein recent years. Through the multi sensors to assist in the communication between human and machine technology more and more, as long as the interactive way enough diversity, interestingly enough, can attract the user holds appreciatively longer. The application of augmented reality technology has also been commercialized with the listing of Glass Google. With the two-dimensional interaction is restricted to interactive 3D break, the way of human-computer interaction showing more and more natural and intuitive interaction behavior, the main implementation techniques include: enhanced augmented reality (AR) and virtual reality (VR). Enhanced reality and virtual reality has the same "characteristic enhancement of true continuity", in a nutshell is the use of the user in a novel 
visualization environment, the fusion of two parts, the real world and the virtual world, allows real physical objects and virtual digital objects interact at the same time. Augmented reality compared to virtual reality, the greater attraction lies in it by the people in real world interaction to control was added on the real world of virtual digital information and the visualization of digital information to enhance and extend the interactive effects. Augmented reality is the advanced speciation of the interactive system based on virtual and interactive features.

Daniel Leithinger from the Media Lab in MIT exhibited the 3D interface of inFORM (Figure 2) in 2014 Tencent Conference.This future haptic screen is composed of 1000 rectangular column sawsand it changes the traditional touch screen technology, so that the user can hand feel and touch the three-dimensional digital information. Through the inFORM, and thousands of kilometers to shake hands, free to move in front of him toss. This product developers think as the human race has evolved to interact with the environment around the same, but with the advent of the information age of the 21st century, touch screen but enable us to miss a tactile feel and touch the truth, can make we feel and the world are closely linked. Research on gesture control continues to mature, the future of the user interface will not be confined to the world of pixels in the screen, the integration of time and shape changes in the 3D touch, will become the future. Exhibited in Milan design week in 2015 a deformation of the table transform (Figure 3Transform 3D deformation desk), successor to officially inform interface, the user can imagine the future deformation furniture form and its interaction with the user and transform can form a wave shape can also be turned the other abstract shapes, even with the dynamic changes of shape to help users to sleep. And cloud server application frenzy, led by Apple, it enterprises have used cloud servers to provide users with data access to information service. Consumers as long as the use of the same set of account and password will be able at any time and in any place, through mobile phones, computers, TV or other mobile device connected to the cloud server, music, video, e-books, office information to share and print. Also in the context of the wisdom of urban construction, the maturity and development of the networking, mixed it cloud, Cloud Architecture, Internet scale it, 3D printing technology also contributed to the emergence of new products in the era of information revolution and further development of human and the virtual digital world of interactive behavior pattern design of Science and technology continue to put forward new challenges.The innovation and integration of science and technologyguarantees the implementation of the concepts of design.

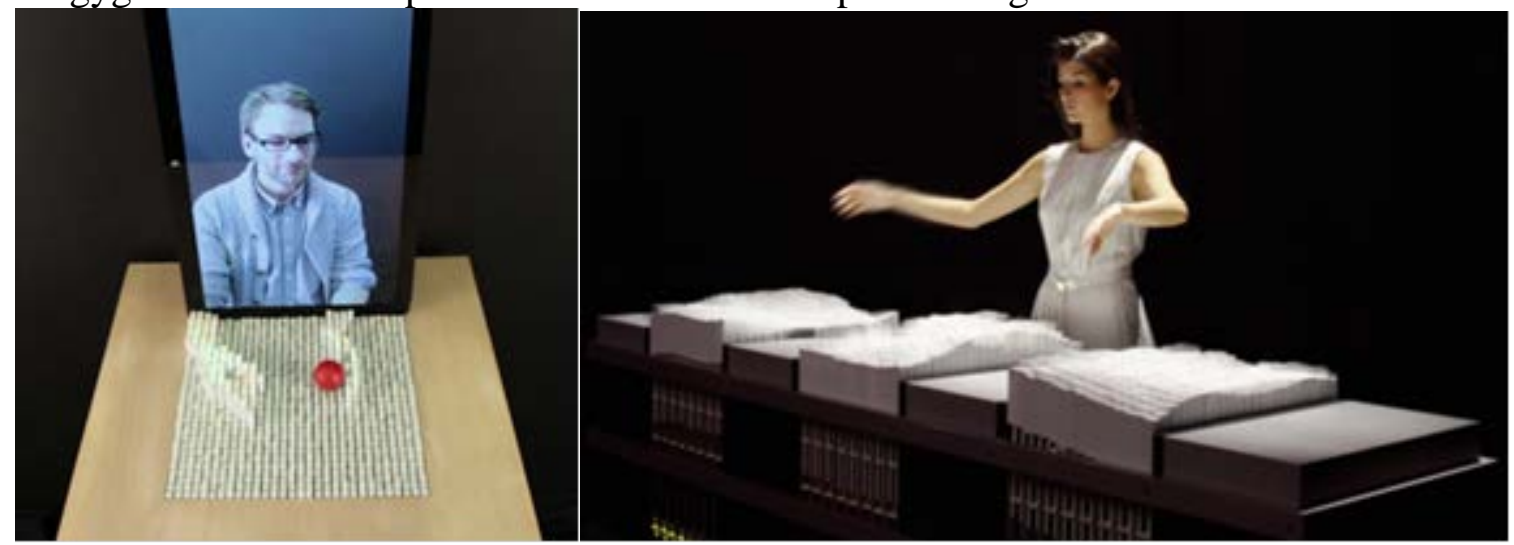

Figure 2 3D Interface of inFORM

Figure 3 3D Deformed Desk

\section{Innovation Driver of Art}

When the function of intelligent equipment has basically met the people's daily life, work demands, the evaluation criteria for product design is no longer limited to improve functional or not, and has entered the attention in the process of pure subjective psychological feeling of stage. Interactive design products from the appearance, function, interactive effect, touch, audio and other aspects are intuitive, specific to become the user can perceive the perceptual existence. Design a good product, to attract users because of curiosity, echocardiography, comfort, beauty and keep the use of products. The art form runs through the whole process of interactive design. Artists in 
interaction design of visual interface design, dynamic design, audio design, interactive design not only need considering in user behavior guidance, also need through the artistic image of products to upgrade and impress per user. Therefore, the artistic image of the interaction design is the unity of the emotional experience and behavior logic of the user in the process of using, and is also the unity of aesthetic activities and ideology.Interaction design art reflected in the appearance design of the product interaction design, visual interface design, and audio interaction design, dynamic design, multi touch experience design and other forms of interaction design. Interaction design aesthetic experience due to the characteristics of the multi dimension, multi form, interactive, under the interaction of visual, auditory, olfactory, tactile and proprioceptive perception system constructed artistic aesthetic experience. Interaction design aesthetic experience needs to design put forward five requirements, including: 1 . the unity of function design and performance design; 2 . the unity of user's demand, experience, the unity of interest to meet and cognitive ability; 3 . the use of the environment adaptive; 4. richness of users' perception and experience in the process of interaction; 5. the possibility of machine learning and adapt to the users' habits in the interaction process.

\section{Conclusion}

Firstly, interaction design is the design of human behavior patterns; secondly, it realizes the design concepts by the innovation and integration of science and technology; and thirdly, it also needs integrating the traditional design language. Through the design language to communicate with the user, it can guide the user behavior. The advent of the era of the information revolution, the boundaries between art and design become more and more fuzzy, art also quietly changing the direction of the development of science and technology, scientific and perfect design rules, abstraction and symbolization of humans and intelligent equipment communication by way of art.Interaction design has changed the characteristics of the traditional art design is concerned with modeling language, brought for the design patterns of human behavior, integrated the design principles of society, art and technology. It promotes the revolutionary change of society, economic, culture and communication.

\section{Acknowledgment}

Project supported by the Humanity and Social Science Foundation of Ministry of Education of China (Gran No.13YJC760028)

\section{References}

[1] Peter G. Rowe, Design Thinking[M]. MIT Press, Cambridge of Massachusetts, 1991.

[2] Shih T K, Wang P P. Intelligent Virtual World: Technologies and Applications in Distributed Virtual Environment [M]. World Scientific Pub Co Inc. 2004;

[3] Smith M J, Salvendy G, Harris D, etal. Usability Evluation and Interface Design: Cognitive Engineering. Intelligent Agents. And Virtual Reality [M]. Lawrence Erlbaum Associates Inc. 2001. 